International Journal of Advanced Trends in Computer Science and Engineering

Available Online at http://www.warse.org/IJATCSE/static/pdf/file/ijatcse2081.32019.pdf

https://doi.org/10.30534/ijatcse/2019/2081.32019

\title{
The Effects of Superhydrophobic Coating Based on Hylocereus Polyrhizus Pigment for Piping Surface
}

\author{
Noraini Marsi ${ }^{1,2,3}$, Nur Athirah Huzaisham ${ }^{1}$. Anika Zafiah Mohd Rus ${ }^{2}$, Anis Nasuha Noor Azman ${ }^{1,3}$, \\ Ahmad Sawal Ithnin ${ }^{4}$, Azrin Hani Abdul Rashid ${ }^{1,3}$, Salwa Mahmood ${ }^{1,3}$, Nurhafizzah Hassan ${ }^{1,3}$ and Rohani \\ Rahmad $^{1,3}$ \\ ${ }^{1}$ Department of Mechanical Engineering Technology, Faculty of Engineering Technology, Universiti Tun Hussein \\ Onn Malaysia (UTHM), Hub Pendidikan Pagoh, KM 1, Jalan Panchor, 84600 Pagoh, Muar, Johor, Malaysia, \\ mnoraini @uthm.edu.my \\ ${ }^{2}$ Sustainable Polymer Engineering, Advanced Manufacturing and Materials Center (SPEN-AMMC), Universiti \\ Tun Hussein Onn Malaysia (UTHM), 86400 Parit Raja, Batu Pahat, Johor, Malaysia. \\ ${ }^{3}$ Innovative Manufacturing Technology Research Group (IMT), Advanced Technology Centre (ATC), Faculty of \\ Engineering Technology, Universiti Tun Hussein Onn Malaysia (UTHM), Hub Pendidikan Pagoh, KM 1, Jalan \\ Panchor, 84600 Pagoh, Muar, Johor, Malaysia \\ ${ }^{4}$ Dhia Legacy - Detergent Manufacturer \& Chemical Cleaning, Sirim Johor Inkubator, No.3, Jalan Teknologi 5, \\ Taman Teknologi Johor, 81400 Senai, Johor,Malaysia
}

\begin{abstract}
The use of coatings has been discovered and introduced to protect the surfaces of any metals used as the piping on plant surfaces. Piping in plant surfaces are exposed to imbalance surroundings and conditions for its lifetime. Basically, surface coating is made up from chemical composition lead to the bigger problem in the future when being installed at the process site undergo chemical changes under environmental conditions and the transformation piping may be more toxic and carcinogenic than the parent molecule. The badly-behaved of toxic effluent discharge by synthetic coating can be counter by using natural coating thus creating more eco-friendly coating surfaces. The study presents the superhydrophobic coating based on dragon fruit (Hylocereus polyrhizus) pigments was formulated and synthesized with different weight by weight (\%wt/wt) concentration of $0.2,0.4$, 0.6 and 0.8 and it consists of three phases to form superhydrophobic coating. The superhydrophobic was successfully provide higher water droplet test (ASTM D5946-04) with concentration of 0.6 (\%wt/wt) which is up to $155.78^{\circ}$. It also reveals the optimum scratch resistance test up to concentration of $0.6(\% \mathrm{wt} / \mathrm{wt})$ the most decent toward scratch resistance of the surfaces..
\end{abstract}

Key words : Coating, Dragon fruit, Piping, Superhydrophobic, Water Droplet..

\section{INTRODUCTION}

The use of coatings has been discovered and introduced to protect the surfaces of any metals used as the piping on plant surfaces. The selection of coating materials should be suited for the designated use and shall be chosen after an evaluation of all relevant facets such as corrosion protective properties
[1], health[[2], safety[3] and environment [4] properties requirements related to application conditions, equipment and personnel and also the availability and economics of coating materials[1].

The motivation of this study is to use dragon fruit as the natural pigment due to its eco-friendly which is completely safe to the environment and non-hazardous to the surroundings. When it comes to natural based, it is totally chemical free because it is made up from natural ingredients. The use of dragon fruit as natural pigment to develop superhydrophobic coating will produce cost effective and energy saving. The colouring properties are important in determining the application efficiency and hence economics[2]. The extraction of pigment from natural based of dragon fruit into surface coating.

The purple colour from dragon fruit (Hylocereus polyrhizus) pigment extracted give the coating colours that is used to differentiate between each working pipe on the process plant. It functions as one of the security measures to avoid any misunderstanding, potential hazards and accidents[3]. The large and various amount of equipment and piping in the plant site requires a system to be used to identify and distinguish between each operating piping to eliminate any chances of hazards and accidents hence reducing operational errors[4]. This research has resulted in the effects of superhydrophobic coating based on dragon fruits pigment for piping surfaces was revealed the good performance in term of scratch resistance, water droplet test and adhesion test that may help in reduce the health effects of toxic exposure.

\section{RELATED WORKS}

Priatni and Pradita (2015) studied about the red dragon fruit pigment. Dragon fruit (Hylocereus polyrhizus) is one of the tropical fruits under the cactus family, Cactaceae. The peels of red dragon fruit are the potential sources of Betacyanin which 
responsible for the red-violet colour. These pigments are also water-soluble and localized in vacuole as bis-anions[5]. The Betacyanin pigments are soluble in water compared to in non-polar solvent that helps in extraction and separation processes of the pigment. The deep purple colour (Betalains) made up from red pigment (Betacyanin) and yellow pigment (Betaxhanthins). The chemical structure of Betacyanin is more soluble in water than in non-polar solvents. The stability of Betacyanin from red dragon fruit peels which is extracted by methanol and water was presented kept in room temperature for 5 hours in Fig.1. The analysis of Betacyanin can be deduced from their chromatographic behaviour, and corroborative data may be retrieved from the analysis of their absorption spectra[6]. This data was proven that there is possibility use dragon fruit pigment into coating applications.

Superhydrophobic coating is a nanoscopic surface layer that has extremely high water repellency. Any kind of water droplet will bead up and bounce off the surface layer of the coating in its original shape. Superhydrophobic is well known for its self-cleaning properties. In superhydrophobic surface, the surface morphology plays a crucial role effecting wettability. Roughening a surface can not only enhance its hydrophobicity due to the increase in the solid-liquid interface[7], but also when air can be trapped on a rough surface between the surface and the liquid droplet. Since air is an absolutely hydrophobic material with a contact angle of $180^{\circ}$, this air trapping will amplify surface hydrophobicity[8]. The superhydrophobic coating has its own properties such as self-cleaning properties, UV resistance and corrosion protection.

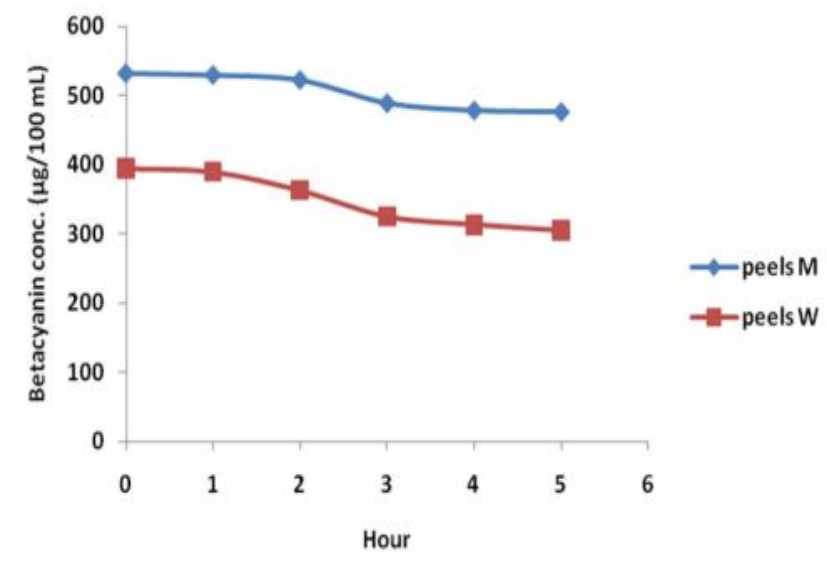

Figure 1: The stability of Betacyanin from red dragon fruit peels (peels M: extract in methanol, peels W: extract in distilled water)[6]

Nimittrakoolchai and Supothina (2008) studied the anti-adhesion and self-cleaning properties of a superhydrophobic film by applying red powder and dust onto it. The superhydrophobic coating was prepared by the deposition of a polyelectrolyte film on a glass substrate, followed by etching in $\mathrm{HCl}$ solution to roughen the surface, and by the deposition of $\mathrm{SiO}_{2}$ nanoparticles onto the etched film. They showed that much of the red powder was still spread on the uncoated surface after cleaning with water droplets as compared to the superhydrophobic surface, which was much cleaner[9]. In a natural environment, surfaces get contaminated very easily and frequently. Cleaning them is time consuming and costly. Therefore, superhydrophobic coating is developed and improvised from time to time to enhance the characteristics. The physical reason of self-cleaning is the joint action of small adhesion of dust particles to the surface and high capillary force acting on the dust particles at water drop-air interface. These properties arise from the combination of the low interfacial energy and their rough surfaces. This combination leads to apparent water contact angles (WCAs) larger than $140^{\circ}$ with low sliding angles and the self-cleaning effect as shown in Figure 2[10].
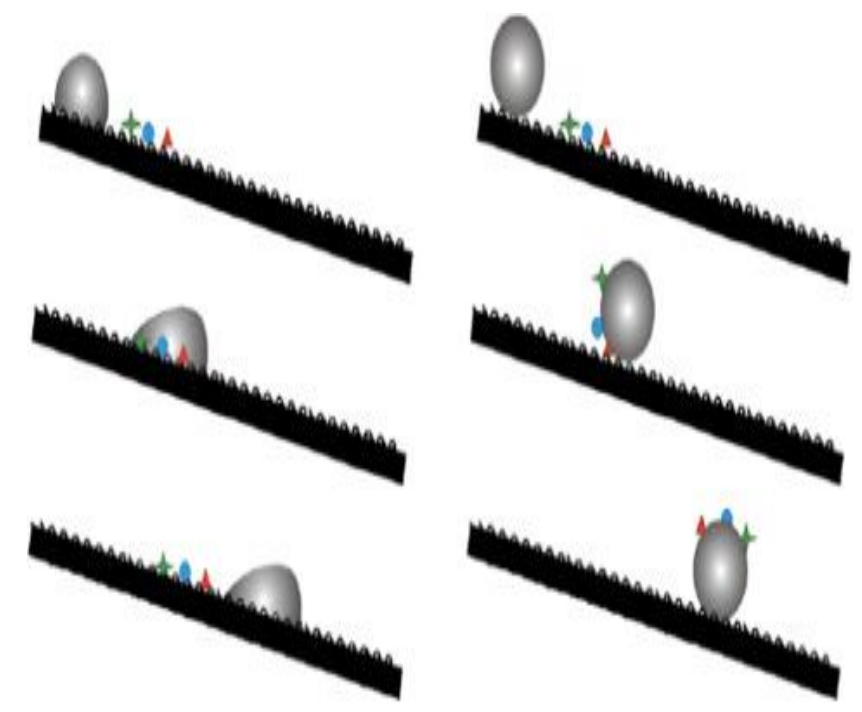

Figure 2: Water droplets rolling off substrates with a normal hydrophobic surface (left) and a self-cleaning superhydrophobic surface (right) through dust particles ${ }^{10}$

\section{METHODOLOGY}

The pigment was prepared by extracting the pigment from the pulp of the dragon fruit. The pulp was blended and the pigment was filtered to obtain the raw pigment. The pigment is then divided into four different concentrations which is 0.2 , $0.4,0.6$ and 0.8 weight by weight (wt/wt) of concentration as shown in Figure 3. Different ratio of water was added to each percentage of dragon fruit pigment concentration as shown in Table 1.

The preparation of superhydrophobic coating is done by preparing solution of components for the coating. In this study, solvent and hardener are used to prepare the mixture of the coating. The ratio of solvent to hardener used in this study is $250 \mathrm{ml}: 12.5 \mathrm{ml}$. The solvent and hardener are then mixed together in a beaker and then is stirred by using magnetic stirrer to ensure both solutions are well mixed[11]. 


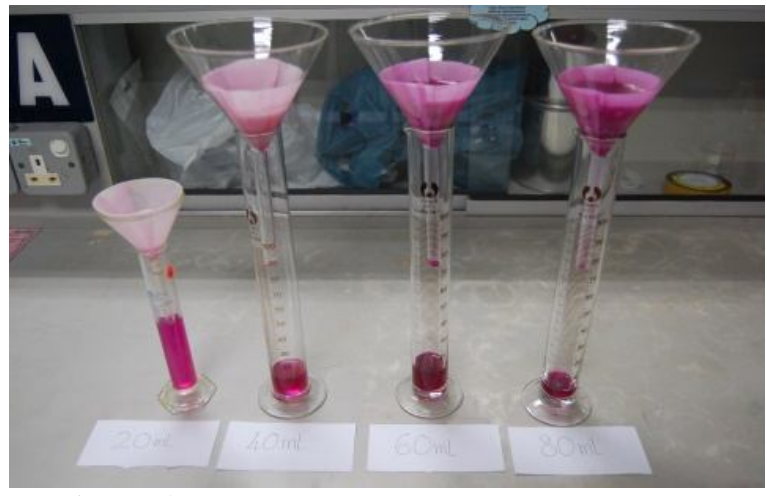

Figure 3: The filtration process of dragon fruits

Table 1: The pigment ratio

\begin{tabular}{|c|c|c|}
\hline No. & Dragon fruit pigment & Water \\
\hline 1 & $20 \mathrm{ml}$ & $80 \mathrm{ml}$ \\
\hline 2 & $40 \mathrm{ml}$ & $80 \mathrm{ml}$ \\
\hline 3 & $60 \mathrm{ml}$ & $80 \mathrm{ml}$ \\
\hline 4 & $80 \mathrm{ml}$ & $80 \mathrm{ml}$ \\
\hline
\end{tabular}

The pigment was applied to the stainless-steel plate by using a paint brush. First stage, the 3 layers of different concentration of pigment was applied on the substrate and then continues for 6 layers and 9 layers of pigment as shown in Figure 4. The purpose of the method is to differentiate and distinguish between each layer of dragon fruit concentration. The sample was left dried for a day before superhydrophobic coating mixture is applied on top of the pigment coating.

The superhydrophobic coating mixture is applied to the plate that has been coated with dragon fruit pigment by using spray gun. The process of coating takes place in the fume chamber for safety measurements. The method of applying superhydrophobic coating is by using spraying techniques to determine the smooth surface coating on the substrate. It has three stages where the first stage is spraying the mixture for 3 layers to all the samples, and then continue with another 3 layers for 6-layer samples and lastly another 3 layers for nine-layer samples. The coating is left to completely dry for three days before conducting any test on the samples.

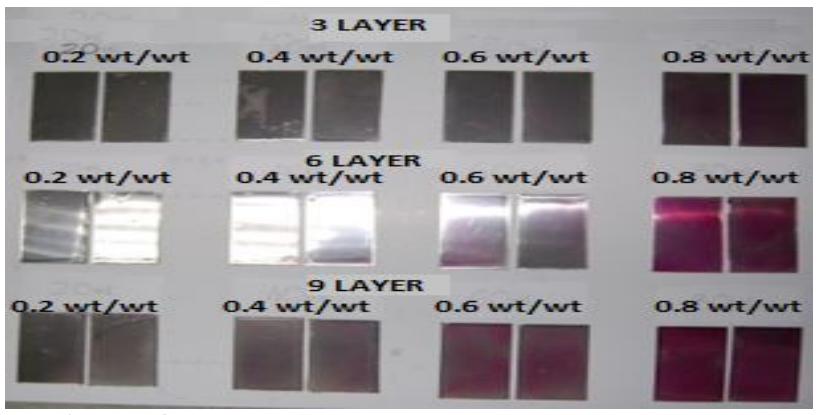

Figure 4: The different concentration of Hylocereus polyrhizus pigment

\section{RESULTS AND DISCUSSIONS}

The water contact angle for water droplet test according to ASTM 5946-04 for superhydrophobic coating should be in between $140^{\circ}$ to $175^{\circ}$. If the water contact angle is less than the desired value, it cannot be considered as superhydrophobic. Therefore, the samples can be considered as superhydrophobic coating as the contact angles obtained are in between range $140^{\circ}$ and $170^{\circ}$. The contact angle for every sample for all Hylocereus polyrhizus concentration for 3 layers, 6 layers and 9 layers are shown in Table 2.

From the table, the water contact angle was obtained for superhydrophobic coating is between range $135^{\circ}$ and $156^{\circ}$. The higher water contact angle test for the layers is in range 140 degrees and 144 degrees. The lower water contact angle is $135^{\circ}$ which is $0.2 \mathrm{wt} / \mathrm{wt}$ of Hylocereus polyrhizus pigment concentration with 9 layer of substrate and the highest water contacnt angle is $156^{\circ}$ which is $0.6 \mathrm{wt} / \mathrm{wt}$ of Hylocereus polyrhizus pigment concentration with 6 layers of substrate. It is clear that angle of contact is vary from one and another and the comparison is as shown in Figure 5.

Superhydrophobic surfaces possessing high advancing water contact angle (WCA) and lower water contact angle hysteresis have concerned because their water-repellent and self-cleaning properties and possible for everyday applications ranging from biotechnology to self-cleaning commodity materials. The superhydrophobic coating gives unique characteristics to the coated surface which is when water dropped onto the surface, it shattered into particles and the rolled off from the surface[12].

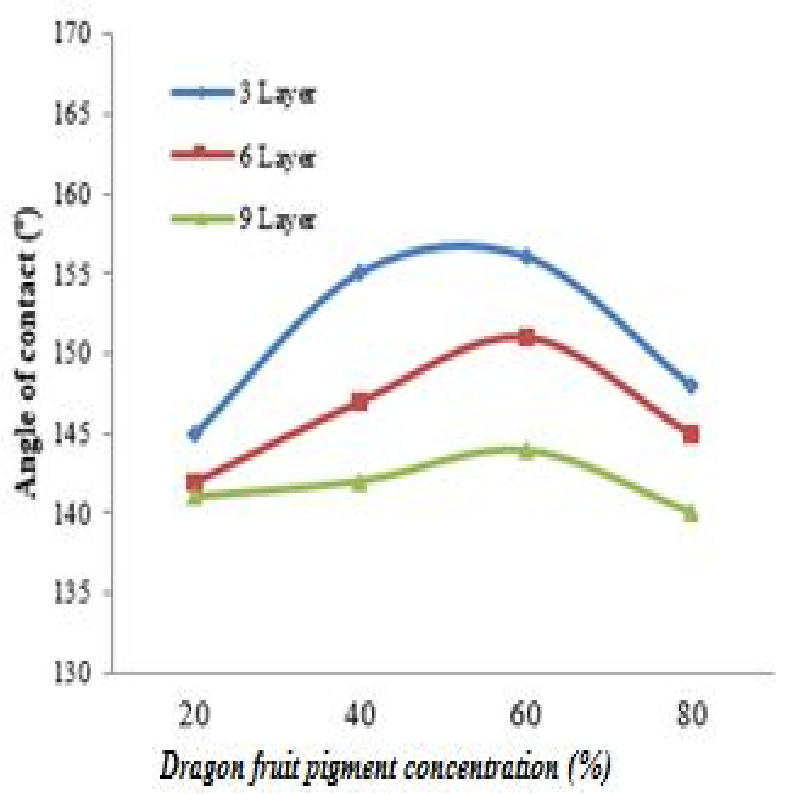

Figure 5 : The average of water contact angle for the samples

Figure 6 shows the superhydrophobic coating bears a good scratch resistance. For $0.2 \mathrm{wt} / \mathrm{wt}$ of Hylocereus polyrhizus 
pigment concentration with three layers of substrate, it started to scratch from $3 \mathrm{H}$ of pencil hardness, for the six layers of substrate, of scratch begin from $4 \mathrm{H}$ of pencil hardness and for nine layers of substrate, it only scratch for $5 \mathrm{H}$ of pencil hardness. For $0.4,0.6$ and $0.8 \mathrm{wt} / \mathrm{wt}$ of Hylocereus polyrhizus concentration for three layers, the scratch resistance is the same which is for $4 \mathrm{H}$ of pencil hardness. For 6 layer of substrate, 0.2 and $0.4 \mathrm{wt} / \mathrm{wt}$ of Hylocereus polyrhizus concentration has the same scratch endurance which is for $4 \mathrm{H}$ of pencil hardness. $0.6 \mathrm{wt} / \mathrm{wt}$ and $0.8 \mathrm{wt} / \mathrm{wt}$ of Hylocereus polyrhizus concentration scratch resistance is slightly better than 0.2 and $0.4 \mathrm{wt} / \mathrm{wt}$ of Hylocereus polyrhizus concentration which is it begin to scratch from $5 \mathrm{H}$ of pencil hardness.

For nine layers of substrate, the scratch resistance for 0.2 and $0.4 \mathrm{wt} / \mathrm{wt}$ is the same and for $0.6 \mathrm{wt} / \mathrm{wt}$, it only began to scratch from $5 \mathrm{H}$. The $0.8 \mathrm{wt} / \mathrm{wt}$ of Hylocereus polyrhizus concentration of superhydrophobic coating is supreme for the scratch resistance test. This scratch resistance test, the different concentration of dragon fruit pigment was affected the performances of the coating. It is shows that the superhydrophobic coating does not scratch until the substrate reaches its yield point, and even then, the coating remains bonded to the surface [13]. The superhydrophobic coating reached it limits when it was scratch by using pencil hardness of $4 \mathrm{H}$ and above.

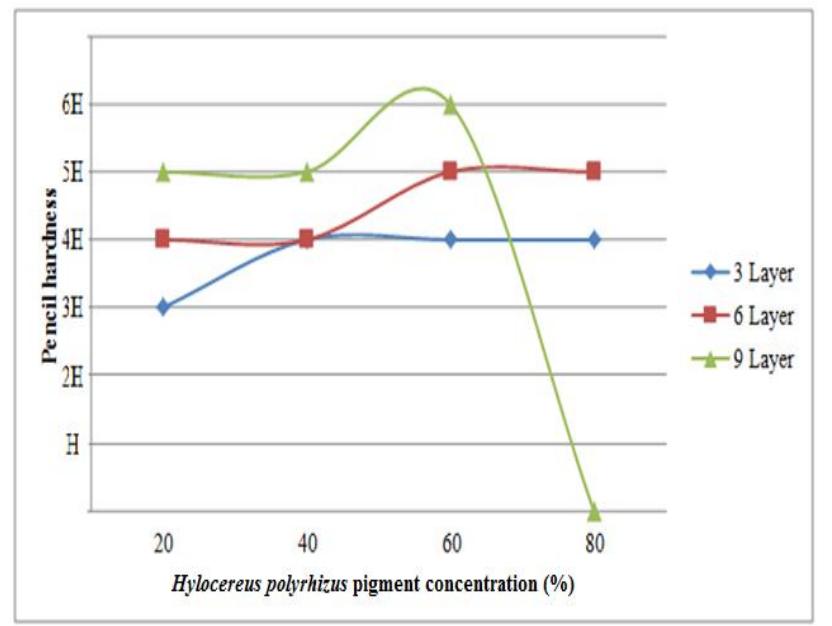

Figure 6: Scratch resistance test for each layer of 0.2, 0.4, 0.6 and $0.8 \mathrm{wt} / \mathrm{wt}$ of Hylocereus polyrhizus pigment.

The result for adhesion resistance test is shown in Table 3. Flaking occurred poorly for samples with 3 layers of superhydrophobic coating. Flaking rate for 3 layers of $80 \%$ Hylocereus polyrhizus pigment concentration is the highest with more than $65 \%$ of coating detached from the substrate.
Table 3: Water droplet test results of different concentration and layer of coating surfaces in carbon steel surfaces

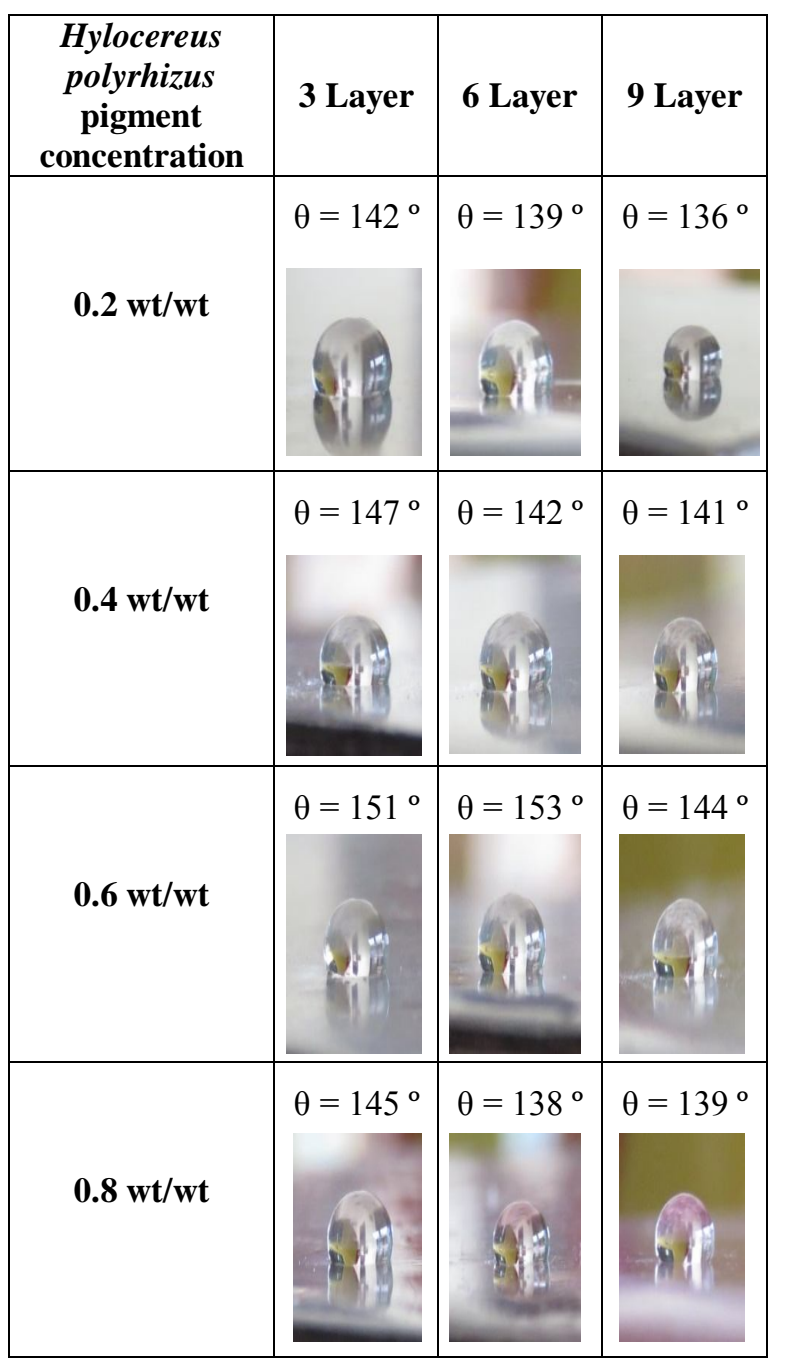

This is because the concentration of Hylocereus polyrhizus pigment is thicker than the other concentration; it binds with superhydrophobic coating tightly and resulting in the detachment of the coating with the highest percentage. For 6 layers of Hylocereus polyrhizus pigment, the flaking was occurred with the highest rate of flaking at $3 \mathrm{~B}$ which is only $5 \%$ to $15 \%$ area from the lattice. For 0.6 and $0.8 \mathrm{wt} / \mathrm{wt}$ of Hylocereus polyrhizus concentrations yield the same result which there is no flaking at the surface. The result obtained was analysed and the comparison is shown in Fig.7. The optimum result was obtained from the adhesion test for 9 layers of coating which is there is no flaking for all the samples with different concentration of Hylocereus polyrhizus. This is due to the higher viscosity inhibits settling and flocculation of the Hylocereus polyrhizus pigments on the substrate [14]. Table 4 shows flaking in supoerhydrophobic coating with different layer of 3, 6 and 9 layers. 


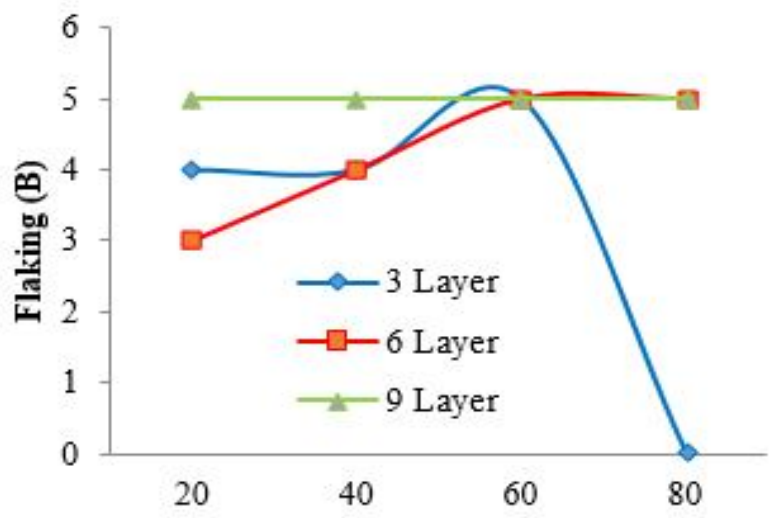

Hylocereus polyrhizus concentration (\%)

Figure 7 : The average flaking range of adhesion test result

Table 4: Flaking in supoerhydrophobic coating with different layer of 3,6 and 9 layers.

\begin{tabular}{|c|c|c|c|c|}
\hline \multirow{2}{*}{ Layer } & \multirow{2}{*}{$\begin{array}{c}\text { Betalain } \\
\text { concentratio } \\
n\end{array}$} & \multicolumn{3}{|c|}{ Classification (B) } \\
\hline & & Test 1 & Test 2 & Test 3 \\
\hline \multirow{4}{*}{3 Layer } & $0.2 \mathrm{wt} / \mathrm{wt}$ & $4 \mathrm{~B}$ & $3 \mathrm{~B}$ & $4 \mathrm{~B}$ \\
\hline & $0.4 \mathrm{wt} / \mathrm{wt}$ & $4 \mathrm{~B}$ & $4 \mathrm{~B}$ & $5 \mathrm{~B}$ \\
\hline & $0.6 \mathrm{wt} / \mathrm{wt}$ & $5 B$ & $5 \mathrm{~B}$ & $5 \mathrm{~B}$ \\
\hline & $0.8 \mathrm{wt} / \mathrm{wt}$ & OB & $2 \mathrm{~B}$ & $2 \mathrm{~B}$ \\
\hline \multirow{4}{*}{6 Layer } & $0.2 \mathrm{wt} / \mathrm{wt}$ & $3 \mathrm{~B}$ & $4 \mathrm{~B}$ & $4 \mathrm{~B}$ \\
\hline & $0.4 \mathrm{wt} / \mathrm{wt}$ & $4 \mathrm{~B}$ & $5 \mathrm{~B}$ & $5 \mathrm{~B}$ \\
\hline & $0.6 \mathrm{wt} / \mathrm{wt}$ & $5 \mathrm{~B}$ & $5 \mathrm{~B}$ & $5 \mathrm{~B}$ \\
\hline & $0.8 \mathrm{wt} / \mathrm{wt}$ & $5 B$ & $5 \mathrm{~B}$ & $5 \mathrm{~B}$ \\
\hline \multirow{4}{*}{9 Layer } & $0.2 \mathrm{wt} / \mathrm{wt}$ & $5 \mathrm{~B}$ & $5 \mathrm{~B}$ & $5 \mathrm{~B}$ \\
\hline & $0.4 \mathrm{wt} / \mathrm{wt}$ & $5 \mathrm{~B}$ & $5 B$ & $5 \mathrm{~B}$ \\
\hline & $0.6 \mathrm{wt} / \mathrm{wt}$ & $5 B$ & $5 \mathrm{~B}$ & $5 \mathrm{~B}$ \\
\hline & $0.8 \mathrm{wt} / \mathrm{wt}$ & $5 B$ & $5 \mathrm{~B}$ & $5 \mathrm{~B}$ \\
\hline
\end{tabular}

\section{CONCLUSION}

In conclusion, the water contact angle results show favorable to the self-cleaning purposes for superhydrophobicity which is in range between $140^{\circ}$ to $156^{\circ}$ up to $0.4 \% \mathrm{wt} / \mathrm{wt}$ of concentrations. Regarding to scratch resistance test, the 0.6 and $0.8 \mathrm{wt} / \mathrm{wt}$ of Hylocereus polyrhizus concentrations yield no flaking at the surface up to 9 layers. This is due to the layer of dragon fruit pigment has proper mixing of multi-component coatings between matrix pigment and epoxy resin that resulted in the effects of superhydrophobic coating based on dragon fruits pigment for piping surfaces was revealed the good performance. It also gives an alternative to reduce toxic coating and help in reduce the health effects of toxic exposure

\section{ACKNOWLEDGEMENT}

The authors would like to thank the Universiti Tun Hussein Onn Malaysia for supporting this project under Contract Grant by UTHM Scheme (Phase 1/.2016), vot U666.

\section{REFERENCES}

1. Mirza, M. M., Rasu, E. and Desilva, A. Surface coatings on steel pipes used in oil and gas industries - a review. American Chemical Science Journal, 13(1) (2016) 1-23 https://doi.org/10.9734/ACSJ/2016/22790

2. Alam, M., Akram, D., Sharmin, E., Zafar, F. and Ahmad, S. Vegetable oil based eco-friendly coating materials: a review article. Arabian Journal of Chemistry, 7(4) (2014) 469-479. https://doi.org/10.1016/j.arabjc.2013.12.023

3. Azhari, M. A., Arith, F., Ali, F., Rodzi, S. and Karim, K. Fabrication of low cost sensitized solar cell using natural plant pigments dyes. ARPN Journal of Engineering and Applied Sciences. 10(16) (2015) 7092-7096. 2

4. Marsi, N., Rus, A. Z. M. and Tan, N, A. M. S. The effects of curcuma longa on the functionality of pigmentation for thin film coating. IOP Conference Series: Materials Science and Engineering, 226(1) (2017) 1-6. https://doi.org/10.1088/1757-899X/226/1/012160

5. Priatni, $S$ and Pradita, A. Stability study of betacyanin extract from red dragon fruit (Hylocereus polyrhizus) peels, Procedia Chemistry 16 (2015) 438-444.

https://doi.org/10.1016/j.proche.2015.12.076

6. Naderi, N., Ghazali, H. M., Hussin, A. S. M., Amid, M. and Yazid, A. M. M. Characterization and quantification of dragon fruit (Hylocereus polyrhizus) betacyanin pigments extracted by two procedures. Pertanika Journal of Tropical Agriculture Science. 35(1) (2012) 33-40.

7. Anis, A. L., Talari, M. K. and Darham, W. Synthesis and characterization of superhydrophobic alumina-silane sol-gel coating. Science letters 10(1) (2016) 24-26.

8. Arote, S., Tabhane, V., Gunjal, S. and Pathan, H. Structural and optical properties of compact $\mathrm{SnO} 2$ thin films by sol gel dip coating. Advanced Science Letters 20 (2014) 1039-1043.

https://doi.org/10.1166/asl.2014.5479

9. Mohamed, A. M. A., Abdullah, A. M. and Younan, N. A. Corrosion behavior of superhydrophobic surfaces: a review. Arabian Journal of Chemistry 8(6) (2015) 749-765. https://doi.org/10.1016/j.arabjc.2014.03.006

10. Zhao, X. D., Xu, G. Q. and Liu, X. Y. Superhydrophobic surfaces: Beyond lotus effects. Bioinspiration (2012) 331-378.

https://doi.org/10.1007/978-1-4614-5372-7_9 
11. Marsi, N, Rus, A. Z. M., Ibrahim, M. R., Samsuddin, S. A. and Rashid, A. H. A. The synthesis and surface properties of newly eco-resin based coconut oil for superhydrophobic coating. Solid State Phenomena. Material and Manufacturing Technology VIII (266) (2017) 59-63.

https://doi.org/10.4028/www.scientific.net/SSP.266.59

12. Levkin, P. A., Svec, F. and Frechet, J. M. J. Porous polymer coatings: a versatile approach to superhydrophobic surfaces. Advances Functional Materials 19(12) (2009) 1993-1998. https://doi.org/10.1002/adfm.200801916

13. Ariono, D. and Wardani, A. K. Hydrophilic polyproplene membrane for biomedical application. Advanced Science Letters 23 (2017) 5713-5715. https://doi.org/10.1166/asl.2017.8810

14. Rus, A. Z. M. Mohid, S. R., Nurulsaidatulsyida, S. and Marsi, N. Biopolymer doped with titanium dioxide superhydrophobic photocatalysis as self-clean coating for lightweight composite. Advances Materials Science and Engineering (2003) 1-9.

https://doi.org/10.1155/2013/486253 